\title{
A Look Back at Hair Restoration through History
}

\author{
Dua K*, Desai NV and Dua A \\ AK Clinics, India
}

*Corresponding author: Dr. Kapil Dua, MBBS, MS, AK Clinics, 2190, Krishna Nagar, Near Aarti chowk, Ludhiana, Punjab - 141001, India, Tel: +919815544207; E-mail: drkapildua@akclinics.com

\section{Review Article \\ Volume 1 Issue 1}

Received Date: August 08, 2017

Published Date: August 19, 2017

DOI: $10.23880 /$ ijtps-16000101

\section{Abstract}

The hair remains an integral part of beauty since centuries in most of the cultures. And loss of hair causes a huge negative psychological impact. Thus, people have been trying to find out one or the other treatment to get rid of the baldness. They have tried a variety of treatments ranging from local application of medicines to shampoos and oral medications but none have been able to give a head full of hair till the modern day hair transplants.

Now, what we see of Hair transplants today has been an interesting voyage of ups and down starting from its application in the rare indications to the common ones nowadays; and the method once found not worthy and had almost extinguished becoming revolutionary with some newer adaptation in recent times.

For most of the world, the modern hair transplant started off with the work of Norman Orentreich in the form of punch grafting in the early 1950s. But there were many more contributions which remained hidden from the medical fraternity at large because of the reasons discussed below. The punch grafting gave way to the mini/micro grafting along with strip removal technique in late 1970s and early 1980s, followed by the era of Follicular Unit Transplantation (also known as FUT) in mid 1990s. This was followed by the latest technique of Follicular unit extraction (also known as FUE) in the 21 st century. This latest procedure has taken the hair transplants to a newer height and acceptability by the most of the patients. In this article, the authors will try to give an overview of this progress with the best of their knowledge based on the data available from various resources.

Keywords: Hair Restoration; Hair transplants; Grafting hair; Follicular unit; Hair transplant surgery

Abbreviations: FUT: Follicular Unit Transplantation; FUE: Follicular Unit Extraction; SAFE System: Surgically Advanced Follicular Extraction; PCID: Powered Cole Isolation Device; CDD: Cole Dissection Device

\section{Era of Punch Grafts}

This started when a dermatologist from New York, Norman Orentreichin the early 1950s pioneered a procedure for grafting hair from the occipital area of scalp onto bald spots. This was done during his investigation about whether common skin conditions showed donor or recipient site dominance. He observed that that the grafts transplanted from occipital scalp survived on the bald scalp. On the basis of his observation, he coined the term "Donor dominance" to explain the survival of graft from occipital area into the bald recipient site and later continued to grow as if it were in its original location. He performed first such surgery in 1952 by using $4 \mathrm{~mm}$ 


\title{
International Journal of Transplantation \& Plastic Surgery
}

punch and published his work eventually in 1959 [1].

Thus, he is considered as the father of modern hair

\author{
transplantation.
}

\section{History from the lost pages}

The earliest written record of Successful hair transplant to treat baldness in humans is from Wurzburg, Germany in 1822 from the work of a medical student named Diffenbach and his surgeon mentor Professor Dom Unger. They performed experimental surgery in animals and in humans. They successfully transplanted hair from one area of a patient's scalp to another area. Professor Unger was said to believe that hair transplantation would make baldness a rarity ${ }^{1}$. But for unknown reasons it never got much popularity and reorganization at that time or even later and the chapter went close with them.

1. Ishrs.org (2017) Historical Overview: 181 Years of Hair Restoration Surgery.

Soon, the word about this wonderful new procedure spread fast. The idea of having natural hair rather than something artificial on their bald scalp fascinated one and all. Many centers in America and Europe started offering hair restoration technique known as "punch grafting." And by 1970, many people took the plunge which later resulted in many scalps resembling "Doll's Head".

\section{History from the lost pages}

Another missed chapter of the same journey started off in the eastern world in Japan during 3rd and 4th decade of the 20th century, but remained unrevealed to the rest of the world for many decades.

Several Japanese dermatologists like Sasagawa ${ }^{1}$ Okuda, Tamura and Fujita had already used small autografts containing hair follicles for the correction of scars and cicatricial alopecias but this knowledge and technique remained hidden from the rest of the world due to the Word war II. TheOther major obstacles were the lack of fast and effective ways of communication and the language barrier as all the literature published by them was in Japanese language. Okuda's paper was published in the year $1939^{2}$ which mentioned the use of self-made sharp circular punches with varying diameters from 1 to $4 \mathrm{~mm}$ for the hair transplantation in the Japanese journal of dermatology, almost 20 years before Orentreich. It contained most of the principles of modern hair transplantation. He reported nearly 200 cases but did not mention male pattern hair loss as an indication, which is perhaps why Orentreich is credited with being the first to use this technique for male pattern hair loss.

${ }^{1}$ Sasagawa M (1923) Hair transplantation (in Japanese) Jpn J Dermatol 30: 493.

${ }^{2}$ Okuda S (1939) Clinical and experimental studies on transplanting of living hair (in Japanese). Jpn J Dermatol 46: 135138.

\section{Era of Mini \& Micro Grafts}

This era started with the beginning of post extraction processing of removed donor punch grafts and then further improvised by the change in the method of removal of donor tissue by removing the entire strip from and donor area instead of punch grafts. It was known by then that the smaller grafts had benefit of delivering more natural looking results than the original punch grafts. Thus, by 1980s smaller grafts were prepared by dissecting the punch grafts into halves or quarters.
But then in early 1990s, Carlos Uebel from Brazil and the Moser clinic in Vienna developed a method of harvesting the donor strip instead of punch grafts followed by preparation of mini and micrografts containing 3-7 hairs by further dissection of strip in to smaller pieces [2,3]. The success and acceptance of this mini/micrografting finally put an end to the era of $4 \mathrm{~mm}$ punch grafting and the new era of the strip harvesting technique begun. The technique was almost similar but independent to what was already described by Tamura. 


\section{International Journal of Transplantation \& Plastic Surgery}

\section{History from the lost pages}

From 1937 to 1943, Hajime Tamura ${ }^{1}$ operated 136 cases for various indications including atrichia vulvae, hypotrichosis and cicatricial alopecia and concluded that the grafting of single hair is possible.

As per his record the "ship shaped" incision was made to excise the scalp tissue followed by suturing of resultant wound similar to what is known as strip harvesting technique today.

After cleaning and excision of extra fat from the tissue it was dissected in to small pieces parallel to the direction of hair shaft and kept in physiological saline. It was similar to preparation of mini/micrografts by dissecting the donor strip in to small pieces.

About the recipient area, he mentioned to use $1 \mathrm{~mm}$ punch and thick needle to create recipient sites in which hair grafts were inserted. He also mentioned that the newly implanted hair would shed off after 2-3 weeks of transplant and would regrow from the same region later on.

Regarding better cosmetic outcome he mentioned that the donor is better if it is as small as possible. He also warned about big donor grafts and resultant unnatural look due to their growth occurring in bundle and suggested that the best outcome would be with single hairs.

Had this information been properly understood by the world beforehand, then many scalps could have been saved from the doll's head look and the history might have taken a different course.

It is even more interesting to know that the facial hair restoration which is gaining popularity nowadays was started by Fujita for eyebrow transplantation way back in 1950 s $^{2}$.

${ }^{1}$ Tamura H (1943) Pubic hair transplantation. Jpn J Dermatol 53: 76.

${ }^{2}$ Fujita K (1953) Reconstruction of the eyebrows (in Japanese) La Lepro 22: 364.

Another major advancement occurred when William Rassman of Los Angeles introduced mega-sessions of over 3000 minigrafts in some cases. He did it with the support of large number of technicians to fasten the graft dissection [4]. To further facilitate and speed up the grafts dissection, then various instruments were developed. They ranged from multiblade knives containing up to ten blades to automatic dissection devices including the one by Boudjema in France in 1992 and Dr. Tony Maugubat in the USA in 1996 [5]. However, due to technical difficulties and more follicular injury, such blades did not gain much popularity and were eventually abandoned.

One of the major events in the field of hair restoration was the use of microscope for graft dissection. It was started by Bob Limmer of Texas in 1987to give an operator a clear view of what to dissect to minimize the follicular injury [6]. Though microscopic dissection made the dissection easy but the major limiting factor was the speed of dissection. The average speed of dissection was only about 150-200 grafts per hour thus requiring more number of staff members to dissect the grafts. As a result, there was much initial resistance to the new microscopic methods and the professionals were slow to take up this meticulous technique. Later, however, David Seager of Toronto wrote extensively and eloquently about the stereomicroscopic dissection technique and following that dissection team of 10 or more assistants became a common practice [7]. Due to this, it was no longer feasible for a cosmetic surgeon with a casual interest in hair restoration to perform these new procedures at a high standard and to assemble, train and keep a large team of surgical assistants together unless the patient flow was regular and therefore the new class of surgeon knows as "hair transplant surgeon" came in to the existence.

\section{Era of Follicular Unit Transplantation}

As the stereomicroscopic dissection of grafts became the norm, as a by product of this, the concept of "Follicular Unit" was introduced. This term recognized the "existence and utility of hairs in naturally occurring groups" and 


\section{International Journal of Transplantation \& Plastic Surgery}

then Bernstein and Rassman in 1995 coined the term "FUT - Follicular unit transplantation" making a discreet place for this procedure [8]. There was an initial resistance from the hair transplant community for this procedure due to more complexity and time consuming nature of the technique, but it slowly gained acceptance. This was mainly due to the increased patient demand supported by improved results being posted on the internet. Eventually by the beginning of 2000, it became the gold standard of surgical hair restoration. Again this further boosted the idea of hair transplant team as it has had become more difficult for one surgeon to complete the entire procedure by himself.
Around the same time line, in the other part of world in the Asia most significant development was done in form of "Implanter" by Choi, et al. of South Korea in 1996 [9]. The beauty of that device was that a unit containing 1-4 hairs could be loaded in it and implanted into the recipient site by just pressing the plunger. Along with this, Professor Jung Chul Kim, also of South Korea, has developed his own version of the Choi implanter that had a different method of action and disposable needles during the same time. So, the journey of implanters started in East in 90s which is now gaining a lot of popularity in the western world.

\section{History from the lost pages}

Here, once again we should note that although the concept of the use of the follicular unit came in vogue in 90's. But it was already described in horizontal scalp biopsies by Headington in his publication in $1984 .^{1}$ Both Rassman and Kim were unaware of that and developed the technique on their own without this information independently.

${ }^{1}$ Headington JT (1984) Transverse microscopic anatomy of the human scalp. A basis for a morphometric approach to disorders of the hair follicle. Arch Dermatol 120(4): 449-456.

Once the strip removal followed by Follicular unit transplant became the common norm of all hair restoration procedures and the patients started getting good natural looking results, the focus started shifting from recipient site to the donor scar left after strip removal. Despite of all precautions and meticulously done suturing the scar used to become visible when patient used to have short hair on the back of the scalp. To overcome this issue a technique of "Trichophytic closer" was introduced by Patric Frechet and Paul Rose as well as Mario Marzolain $2005[10,11]$. In this technique, one of the wound edges was de-epithelialized so that the hair from that edge would grow through the scar tissue and reduce the appearance of the scar at donor site. But still some patients used to develop wide, visible scar after couple of months to years and some from the beginning only. So now slowly, the focus started shifting to decrease the visibility of the linear scar in the which led to the beginning of an era of Follicular Unit Extraction.

\section{Era of Follicular Unit Extraction}

This started off with the manual removal of the individual follicular units from the donor scalp with the smaller sized punches by Bernstein and Rassman in 2002. They named this procedure as "Fox procedure."The idea of extraction of individual follicular units was based on the principle that the area of attachment of arrector muscle to the follicular unit is the tightest zone [12]. Once this is made loose and separated from the surrounding dermis, the inferior segment could be extracted easily. This resulted in tiny, multiple, diffusely scattered and barely visible scars rather than creating a linear visible scar. This was very encouraging especially for those who did not want a linear scar on their back [13]. Thus, the history was about to repeat itself by re-reaching to the point from where all this was started. This technique described by Rassman was inspired by and a refined version of the work of Masumi Inaba of Japan who described the use of a 1-mm needle for removing follicular units in 1988.

Now, even though it was proven by Rassman that follicular units can be extracted by tiny punches still there were challenges in the path in form of high follicular transections and slow speed of extraction and different surgeons were working hard to find a way to pass it.

The first solution came in the form of reduction of the follicular transection rate by the introduction of the 2 step dissection technique by Jim Harris in 2004 known as "A three-step manual process" or "The SAFE System" (Surgically Advanced Follicular Extraction system). In this technique, an initial superficial incision was made with the use of a sharp punch. This was followed by the use of a dull punch to deepen the incision to the desired depth to separate the follicular unit [14]. It turned out to be a breakthrough in terms of reduction of follicular 


\section{International Journal of Transplantation \& Plastic Surgery}

transections and helped to popularize the FUE technique but still it remained a slower technique as the entire procedure was carried out by manual punches and it was only possible to extract only few hundreds grafts in a day so many did not consider it as the first line treatment for the hair restoration of the scalp except to repair the donor scar after strip surgery or to treat smaller area [15].

This limitation of speed of extraction was overcome by the development of initial power assisted device by John Cole in form of his first oscillating extractor in May 2006 followed by Masamitsu Ondain 2008 and later by James Harrisin 2009 in the form of Harris Power Safe System $[16,17]$. This put the FUE in new momentum by increasing the speed of extraction and reducing the follicular transections. Now it was possible to perform surgery with more number of grafts in single session by follicular extraction method.

However, the hunger for having better and more sophisticated technique has led to more development in the field of hair Restoration in the form of suction assisted devices and robotics in the field of hair restoration. An example of the former was the introduction of Neograft in 2010 and the latter, ARTAS robotic system in 2011 [18].

Once the FUE was established as an effective method of extraction the research was directed towards the further lowering down the transection rate and ease out the process of extraction by making various changes in the dissecting tool. So in such attempts various punches and extraction systems/devices have been developed across the globe. Some of the examples of such innovations have been the PCID (Powered Cole Isolation Device) and the latest CDD-Vortex (Cole Dissection Device V6) by Dr. John Cole, Harris S.A.F.E. System along with latest Hex punch by Dr. James Harris, Trevellini FUE system by Dr. Trivellini; Trumpet punch and the Waw system by Dr. Jean Devroye, Flat punch by the author himself and many more.

\section{Era of Body Hair as Additional Source of Donor Graft}

As popularity and acceptability of hair transplant was reaching new peaks, the challenge of availability of limited donor grafts in patients with advanced baldness was faced by many hair transplant surgeons. FUE brought the new hope in such patients by expanding the donor area from scalp to the other hair bearing body sites from where it was not possible to take the grafts with strip removal technique. Though body hair transplant is relatively newer technique being practiced increasingly, the first recorded case of successful body hair transplant was in 2001 by Hirai et al. Ray Woods of Australia first tested body hair transplant and found it effective as early as in 1998 and published it in 2004 [19,20]. And the scientific evidence of recipient site influence was demonstrated by Tommy Hwang in his paper in 2002 which gave legitimacy to the technique of body hair transplantation technique [21]. So the concept of body hair transplant was actually not a newer one but popularized in the era of FUE due to ease of extraction by motorized devices.

\section{Summary}

Surgical hair restoration has made many gains in the last half century. Whereas in the past, plugs, scalp reductions, and flaps may have dominated the surgical discipline and resulted in patient dissatisfaction, hair surgeons are now able to create natural frontal hairlines that are indistinguishable from native or original hairlines. Donor harvesting using FUE has made significant inroads with the automation of this surgical technique in the last several years. But the role of FUT still remains in some cases like the patients with thin hair, advanced cases of baldness, African hair and women hair transplant.

Along with the growth of FUE, new challenges have also come up in the form of non physicians and unlicensed people doing the surgery. Physicians need to be aware that allowing nonphysicians to remove human tissue, monitor sedated patients, treat intraoperative complications, and exclusively perform hair transplant surgery without a physician's presence and direct oversight is unlawful and unethical.

In the end, I would like to conclude by saying that the hair surgery specialty is a rewarding, exciting segment of the cosmetic surgery practice. But it requires dedication, devotion, enthusiasm and skills to give natural looking results.

\section{References}

1. Orentreich N (1959) Autografts in alopecias and other selected dermatological conditions. Ann NY Acad Sci 83: 463-479.

2. Uebel C (1992) 1000 grafts per session. Hair Transplant Forum 3: 9-12. 


\section{International Journal of Transplantation \& Plastic Surgery}

3. Hugeneck J, Kokott R (1992) Non-tufted incisional slit grafting. Hair Transplant Forum 3: 6-7.

4. Rassman W (1993) Mega-transplants in transition. Hair Transplant Forum 3: 11.

5. Boudjema P, Boolauch S (1996) Automated hair transplant system. In: Stough DB, Haber R (Eds.), Hair replacement surgical and medical. Philadelphia: Mosby, pp. 370-374.

6. Limmer R (1991) Bob Limmer does it all one hair at a time. Hair Transplant Forum Int 2: 8-9.

7. Seager D (1996) Binocular stereoscopic dissection microscopes should we all be using them? Hair Transplant Forum Int 6: 2-5.

8. Bernstein R (1995) Follicular transplantation. Int J Aesth Restor Surg 3: 119-32.

9. Choi JC, Kim JC (1996) The Choi hair transplanter. In: Stough DB, Haber R (Eds.), Hair replacement surgical and medical. Philadelphia: Mosby, pp: 125-127.

10. Frechet P (2005) Donor harvesting with invisible scars. Hair Transplant Forum Intl 15(4): 119-120.

11. Marzola M (2005) Trichophytic closure of donor area. Hair Transplant Forum Intl 15(4): 113-116.

12. Rassman WR, Bernstein RM, McClellan R, Jones R, Worton E, et al. (2002) Follicular unit extraction: minimally invasive surgery for hair transplantation. Dermatol Surg 28(8): 720-728.
13. Dua A, Dua K (2010) Follicular unit extraction Hair transplant. J Cutan Aesthet Surg 3(2): 76-81.

14. Harris JA (2006) New methodology and instrumentation for follicular unit extraction: lower follicle transection and expanded patient candidacy. Dermatol Surg; 32(1): 56-62.

15. Knudsen R (2011) Is FUE a repair technique or small case technique rather than a first option for MPM? Hair Transplant Forum International 21(6): 192.

16. Onda M, Igawa HH, Inoue K, Tanino R (2008) Novel technique of follicular unit extraction hair transplantation with a powered punching device. Dermatol Surg 34(12): 1683-1688.

17. Harris J (2009) Harris Power Safe System, ISHRS meeting.

18. Harris JA (2012) Robotic assisted follicular unit extraction for hair restoration: case reports. Cosmet Dermatol 25(6): 284-287.

19. Hirai T, Inoue N, Nagamoto K (2001) Potential use of beards for single-follicle micrografts: convenient follicle-harvesting technique using an injection needle. Ann Plast Surg 47: 37-40.

20. Woods R, Campbell AW (2004) Chest hair micrografts display extended growth in scalp tissue: a case report. Br J Plast Surg 57(8): 789-791.

21. Hwang S, Kim JC, Ryu HS, Cha YC, Lee SJ, et al. (2002) Does the recipient site influence the hair growth characteristics in hair transplantation? Dermatol Surg 28(9): 798-799. 